\title{
Research On Supplier Evaluation And Selection Of Green Procurement
}

\author{
Wang Xiaobin \\ School of Economic and Management \\ Shenyang Aerospace University \\ Shenyang China
}

\author{
Pan Yuanyuan \\ Northern Technology College \\ Shenyang Aerospace University \\ Shenyang China
}

\begin{abstract}
With the rapid development of social economy, Human material civilization greatly improved at the same time, The resources of the earth is decreasing, Human survival environment is also facing a huge threat. Therefore, in the economic globalization and the protection of the ecological environment, the enterprise should undertake the social responsibility. Green purchasing is an important part of the green supply chain management, Green supply chain management, And can reduce cost through coordination and cooperation with suppliers, Reduce the use of hazardous substances, Improve the ability to response market rate, To enhance the competitiveness of enterprises, establish a corporate image of environmental protection. Therefore, the supplier selection is the core content of green procurement, green procurement is the first link, through the selection and evaluation of suppliers can further reflect the enterprise green procurement practice level. The paper will research the before, to study the supplier selection and evaluation of the enterprise from the angle of green purchasing, using analytic hierarchy process, set up a supplier evaluation index system and scheme evaluation model, thus providing methods and selection of supplier green procurement evaluation.

Keywords: Green procurement; Supplier selection; The
\end{abstract} expert scoring method; Analytic hierarchy process.

\section{OVERVIEW OF GREEN PROCUREMENT}

\section{A. Meaning of green procurement}

Currently, green procurement has not been given a uniform definition.

This article defines green procurement as: green procurement is a series of behaviors taking full account of environmental factors, ensuring the minimum impact of purchasing raw materials to environment and the minimum material consumption from the aspect of supply chain. It includes a series of processes from supplier selection and evaluation, supplier operation and management to recycling and re-use.

\section{B. The importance of supplier selection concerning green procurements}

Selection of suppliers is an important decision. Choosing the right suppliers and their long-term cooperation in the supply chain, can reduce the product cost, shorten delivery, increase flexibility, and improve the competitiveness of enterprises. Through close cooperation with supplier concerning the green procurement management, establish environmental image for cooperates and improve the competitiveness. In particular, reduce waste of raw materials, reduce transaction costs, reduce waste disposal costs and increase market share, etc.

\section{Research status of selection methods concerning green procurement}

Although green procurement is a relatively new study field, however, domestic and foreign scholars have conducted some meaningful explorations on the evaluation index of suppliers concerning green procurement. Supplier selection as the core of green procurement has gone through three stages: qualitative methods, quantitative methods, combination of qualitative and quantitative methods. Generally, these methods include: intuitive judgment method, tendering method, select the method of negotiation, procurement cost linear weighting method, AHP, fuzzy comprehensive evaluation method, data envelopment analysis, genetic algorithms, neural network algorithm.

\section{METHODS AND STEPS OF SUPPLIER SELECTION CONCERNING GREEN PROCUREMENT}

\section{A. Classification of supplier}

Overall, supplier classification is an important part of supplier selection and evaluation system concerning the green procurement. It determines which suppliers should develop a strategic partnership with, which can be extended enterprise business with, which can maintain the status quo, which suppliers should be eliminated, and which suppliers are still unidentified.

1. Strategic supplier means that the supplier has important strategic meanings for the company's development. For example, they provide technical patented products or services, and provide the key part of the company's core products. So they can be one and only one supplier, and their presence is essential to the development of the company. The cost of replacing such suppliers is very high and some even impossible to replace.

2.The preferred supplier means that cooperate is more willing to cooperate although you can get the product or service from other providers, which is the fundamental difference with strategic suppliers. Preferred supplier is the overall performance based on the suppliers.

3. Inspection suppliers usually is the first supplier to provide a variety of products or services. If there is not enough understanding about the supplier, one-year 
inspection and study are needed. After completion of the study, upgrade to a preferred supplier or eliminate the vendor.

4. Negative selection of suppliers should no longer get a new product, but the company does not actively eliminate existing businesses. As the main product life cycle, suppliers will naturally be eliminated. In the case of good performance, keep good relationship without destroying the balance.

5. Voluntary withdrawal of suppliers, this is the most extreme example. The suppliers must prevent "life and death struggle". Once vendors know that their existing business is removed, they may have to take extreme measures, such as raising prices or suspension, or poor performance. So ensure that the other supply channels have been opened before action.

\section{B. Principles of supplier selection concerning green procurement}

Selecting the appropriate vendor as long-term partner concerning green procurement is the foundation of enhancing the management level of supply chain and elements of improving corporate performance. Improper supplier selection will not only affect the company's profitability, but also lose the opportunity to collaborate strategically with other business, which may inhibit the improvement of enterprise competitiveness, and also prevent the enterprises from going faster and farther. Principle of supplier selection concerning green procurement:

1) Principle of effective supplier classification

In the selection of suppliers concerning green procurement, we should focus on the effective and clear classification. Due to the increasing competition, companies are unlikely to assess and select suppliers without reason. According to the importance and costs, the classification of suppliers can evaluate the suppliers with more resources, reduce the selection costs, improve work efficiency and gain competitive advantages.

2) Principle of competitive strategy

Competition is comprehensive and long-term process. The company's competitive strategy can define the company's products and services. Meet customer demand with new products, invest on research and development of the new technology, sharing, mutual benefit and common goals, and implement and improve challenging plan according to the objectives, a clear mutual recognition agreements at all levels have the appropriate communication, long-term relationships choose to strengthen and improve the competitiveness of the supply chain, be consistent with the supply chain's corporate culture and business philosophy so that it can effectively improve the ability of supply chain and reduce transaction costs.

\section{3) The principle of win-win}

In the supply chain environment, companies cooperation can bring benefits to both parties, selection advantages of the two parties will achieve win-win situation between enterprise and suppliers. In today's market, the competition is becoming increasingly fierce, and competition in the future will be in the supply chain.

\section{Steps of supplier selection}

Facilitate enterprises' quick response to market demand, and maintain their competitive advantage. The following steps are mainly used in selecting suppliers:

\section{1) Market research}

Analyze changes in the competitive environment in order to achieve a sustainable competitive advantage. In the fierce market competition, enterprises must be clear about competitive strategy and core competitiveness. By analyzing the industry structure and value chain, find their competitive position and core competitiveness ability, therefore, in selecting suppliers, we must first analyze the core competitiveness of enterprises, distinguish core business and outsourcing business.

2) Classification of suppliers

Initially identify the scope of supplier selection under green procurement, and carry out preliminary overall classification. The main two objectives of this course: First, choose different types of providers, in order to meet the need of green procurement and improving competitiveness. Second, companies can save the selection costs. All requirements in the enterprise, some vendors are only in a secondary position, whose products are very easy to find a replacement or source, and not easy to improve competitiveness. Therefore the vendors don't have to be fully in accordance with the strict selection. Classification is helpful to improve efficiency and reduce costs of vendor selection.

3) Determine vendor selection targets and index evaluation system

The targets and index evaluation system of supplier selection are not just a simple evaluation and system; it is an important process of enterprise business process reengineering. Establish substantive goals of supplier selection and index evaluation system is the premise. Supplier index evaluation system is the basis and standard for comprehensive enterprise evaluation, is a complex system to reflect target requirements of different conditions in their own and the impact on the environment.

4) Establish supplier selection evaluation team

In a competitive market conditions, the formation of cross-functional teams, from the perspective of the supply chain, determine vendor selection strategies and a strict implementation is very necessary. Supply chain partners not only are responsible for purchasing, but also involve the common task of various departments and many business processes. Team members must have team spirit, and has a certain expertise.

5) Comprehensive evaluations to suppliers

After the rough selection of suppliers, we can carry out a comprehensive evaluation to suppliers by using specific technologies and tools. Supplier evaluation is the core work in the supplier selection concerning green procurement. First, enterprises establish a comprehensive evaluation index system of supplier selection based on their actual situation, as suppliers should be evaluated differently under different circumstances. Second, determine the weight of each index system weight by AHP. Finally, select appropriate method for supplier selection to evaluate various suppliers and rank the suppliers.

After the comprehensive evaluation of the supplier selected, if the selection is successful, you can implement 
vendor partnerships; if there is no selection, you need to go back step three to expand the scope of supplier selection for a new round of selection.

\section{6) Establish strategic partnership}

More and more companies realize that establishing long-term strategic partnership can get a long-term competitive advantage. Placing small-batch orders in the selection of suppliers, asking for samples to try and test. If qualified, sign quality and long-term purchase contracts; if not, give some technical guidance to cooperate with the corporate strategy. Focus more on the long-term stability and efficiency of procurement and supply, combine with performance management, and carry out step by step in a planned way. After establishing the cooperation relations with suppliers concerning green procurement, determine whether the partnership concerning green procurement suppliers will change in accordance with the changes of business needs. After establishing steps, due to the changes in demand, determine whether the partnership of supply chain will be changed in a corresponding way.

\section{AHP (Analytic hierarchy process) combined with expert scoring method to determine the weight}

\section{1) Construction of judgment matrix}

First, the selection of the experts, these experts should have extensive knowledge and experience. Judge the relative importance of each factor in each level by AHP, and this judgment can be expressed by introducing appropriate scale values; write out the judgment matrix and profoundly analyze the specific problems, and decompose the various factors related according to different attributes one by one from top to bottom; each factor of the same level is not only attached to or has influence on the factors of upper level, but also dominates the factors of the lower level; the lowest level is usually the program, and one or several levels exists in the middle, which is known as the criterion level. According to the elements of previous level, judgment matrix is the relatively important comparison between factors of this level. Judgment matrix is formed by a number of experts filling the consulting table. The nature of expert advice lies in the transformation of extensive knowledge and experience into useful information for decision-making through paired comparisons of many relevant factors.

Assuming element $\mathrm{Bk}$ as a guideline, dominates the elements of the next level $\mathrm{C} 1, \mathrm{C} 2, \mathrm{C} 3 \cdots \cdots \mathrm{Cn}$; the purpose of AHP is to give $\mathrm{C} 1, \mathrm{C} 2, \mathrm{C} 3 \cdots \cdots \mathrm{Cn}$ appropriate weight under the guideline of $\mathrm{Bk}$ and in accordance with their relative importance. Of $\mathrm{n}$ elements, we get the paired comparison matrix $\mathrm{C}=(\mathrm{Cij}) \mathrm{m} \times \mathrm{n}$ 。, of which $\mathrm{Cij}$ indicates the relative importance of factor I and factor $\mathrm{j}$ to goals. Obviously $\mathrm{C}$ has the following properties:

$$
\left\{\begin{array}{l}
\boldsymbol{C}_{i j}>0 \\
\boldsymbol{C}_{i j}=1 / \boldsymbol{C}_{i j}(i \neq j) \\
\boldsymbol{C}_{i j}=1(i=j)
\end{array}\right.
$$

View the results of expert judgment and calculate the average value and the deviation of each element of the judgment matrix, of which $t$ represents the number of experts. The mean value of each element:

$$
C_{i j}=\frac{1}{20} \sum_{t=1}^{20} C_{i j}
$$

Calculate the sum of square of the deviation to represent the concentration of data distribution, mapping out the difference between the true value and the estimated amount. Calculate average score of each element in the matrix scored by 10 experts, in which the difference between expert score and average score of each element is called deviation. Deviation reflects the difference of the element between the expert and all the other experts. Deviation:

$$
d_{i j}=\frac{1}{20} \sum_{t=1}^{20}\left(c_{t i j-\bar{c}}\right)^{2}
$$

Then set a standard for the deviation of each element in advance, send the results of expert scoring and additional information to the experts, and ask for the new judgment matrix on the new basis from the experts. If the deviation of each element does not exceed a given standard, then this case illustrates that the views of experts are consistent Repeat the third and fourth step if deviation of each element exceeds the given standard.

Finally, judgment matrix obtained on the basis of views of the experts is as follows:

$C=\left[\begin{array}{l}\frac{1}{20} \sum_{t=1}^{20} c_{t 11}, \frac{1}{20} \sum_{t=1}^{20} c_{t 12} \ldots \frac{1}{20} \sum_{t=1}^{20} c_{t 1 n} \\ \frac{1}{20} \sum_{t=1}^{20} c_{t 21}, \frac{1}{20} \sum_{t=1}^{20} c_{t 22} \cdots \frac{1}{20} \sum_{t=1}^{20} c_{t 2 n} \\ \cdots \\ \frac{1}{20} \sum_{t=1}^{20} c_{t n 1}, \frac{1}{20} \sum_{t=1}^{20} c_{t 11} \cdots \frac{1}{20} \sum_{t=1}^{20} c_{t n n}\end{array}\right.$

2) Calculate weights and Maximum Eigen value:

Calculate weight $\mathrm{W}$, and normalize each column vector of matrix $\mathrm{C}$

$$
\overline{b_{i j}}=\frac{b_{i j}}{\sum_{k=1}^{n} b_{i j}},(i, j=1,2, \ldots, n)
$$

Add the normalized matrix in each column by row 


$$
\overline{W_{i}}=\sum_{j=1}^{n} \overline{e_{i j}},(i=1,2, \ldots, n)(6)
$$

Normalize the vector :

$$
\begin{aligned}
& W_{i}=\left(\overline{w_{1}}, \overline{W_{2}}, \ldots, \overline{w_{n}}\right)^{T} \\
& W=\frac{\overline{w_{i}}}{\sum_{j=1}^{n} \overline{w_{j}}},(1,2, \ldots, n)
\end{aligned}
$$

Calculate the Maximum Eigen value

$$
\lambda_{\max }=\sum_{j=1}^{n} \frac{(C W)_{i}}{n W_{i}}
$$

Of which, is the ith component of vector $\mathrm{CW}$

3) Consistency test

Judgment consistency means that judging the importance of indicators, the consistency test of the structured judgment matrix is done to avoid contradiction and keep the consistency of respective judgments.

Calculating formula of consistency indicator:

$$
C I=\frac{\lambda_{\max }-n}{n-1}
$$

Consistency proportion

$$
C R=\frac{C I}{R I}
$$

Where RI is a one-time indicator to judge the average random of matrix. Value of RI can be obtained in Table 2.3:

(Coefficient table of RI)

\begin{tabular}{c|c|c|c|c|c|c|c|c}
\hline 1 & 2 & 3 & 4 & 5 & 6 & 7 & 8 & 9 \\
\hline 0.00 & 0.00 & 0.58 & 0.90 & 1.12 & 1.24 & 1.32 & 1.41 & 1.45 \\
\hline
\end{tabular}

When CR> 0.10, it is considered necessary to adjust the judgment matrix so that it has a satisfactory consistency. Otherwise, it's considered judgment matrix has satisfactory consistency. After the completion of overlay operation, you can get the relative importance weights of lowest level of each alternative uppermost layer of the target value. After ranking the weights uniformly in order of size, you can get the best solution (best supplier), the second best solution and the worst solution.

\section{CONCLUSION}

Green procurement should be used as a long-term strategy for the enterprise; in practice, it can actively promote the implementation of green supply chain. The selection of supplier concerning green procurement occupies a decisive position in the supply chain.

Although through literature review and expert consulting, for better practicability and applicability, this paper didn't build their own index system and evaluation model basing on the actual industries and enterprises. After selecting suppliers, further researches are required on how to improve and maintain relationships with suppliers, such as the coordination of benefits and performance evaluation of supplier evaluation selection.

\section{REFERENCES}

[1] Wang Yongbo. Research and application of AHP under green procurement in the supplier selection [J], Internet Fortune. 2009

[2] Liu Bin, Lan Ying. An Empirical Study of the type of vendor selection and firm performance in green procurement $[\mathrm{J}]$, Business Studies 2009

[3] Hou Fangniao. Supplier selection and evaluation in green procurement [J]. Beijing: logistics technology 2007

[4] Liu Ming. Study on green supply chain core manufacturing business supplier selection and coordination strategy [D]. 2010

[5] Cao Xiuying, Liang Jinguo. Application of rough set theory in the supply chain partner selection $[\mathrm{J}]$. Science of science and management, 2002

[6] Miles,Cobin. Environmentalmarke-ting: a sokrceofreputationa, competitive and finan-cial advantage [ J]. Journal of Business Ethics.Dourdrecht 2000

[7] HumPhreysPK,WongYK.Inergratingenvironmentalcriteriaintothes uPPlierselectionProeess[J].JournalofMaterialsProcessingTeehnolog y,2002 